\title{
Microbiota: Host Interactions in Mucosal Homeostasis and Systemic Autoimmunity
}

\author{
Randy S. Longman, ${ }^{1,2}$ Yi Yang, ${ }^{1}$ Gretchen E. Diehl, ${ }^{1}$ SAngwon V. Kim, ${ }^{1}$ \\ AND DAN R. LiTTMAN ${ }^{1,3,4}$ \\ ${ }^{1}$ The Kimmel Center for Biology and Medicine of the Skirball Institute, New York University \\ School of Medicine, New York, New York 10016 \\ ${ }^{2}$ The Jill Roberts Center for Inflammatory Bowel Disease, Department of Medicine, Weill-Cornell \\ Medical College, New York, New York 10021 \\ ${ }^{3}$ Howard Hughes Medical Institute, New York University School of Medicine, New York, New York 10016 \\ ${ }^{4}$ Correspondence: dan.littman@med.nyu.edu
}

\begin{abstract}
The vertebrate intestinal tract is colonized by hundreds of species of bacteria that must be compartmentalized and tolerated to prevent invasive growth and harmful inflammatory responses. Signaling initiated by commensal bacteria shapes antigenspecific mucosal and systemic adaptive immunity. A distinct type of effector $\mathrm{CD} 4^{+} \mathrm{T}$ cells, Th17 cells, have a key role in coordinating the inflammatory immune responses that afford protection to pathogens at the mucosal interface. Balancing this powerful inflammatory response, regulatory $\mathrm{T}$ cells limit collateral damage and provide antigen-specific tolerance to both food and microbial antigens. Here, we discuss the implications for how the microbiota as a whole contributes to compartmentalization from the host and how individual constituents of the microbiota influence the functions and repertoire of effector T cells and organ-specific autoimmune disease.
\end{abstract}

More than a century ago, Elie Metchnikoff hypothesized that intestinal microbes maintained the balance between pro- and anti-inflammatory responses and that disease results from an alteration in the microbiota (Metchnikoff and Mitchell 1907). The discovery and molecular characterization of the evolutionarily conserved innate pattern recognition machinery, including toll-like receptors (TLR) adapted to detect microbial components, offered mechanistic detail for microbial activation of mucosal immunity (Iwasaki and Medzhitov 2004). Although these innate mechanisms are crucial in protecting the host from pathogen invasion, unchecked activation has the potential to result in harmful autoimmunity.

Unique structural components of the mucosal barrier, including mucins and specialized epithelial cells, create a physical barrier between the microbial community and the host immune system, which prevents unrestrained activation of innate and adaptive immunity at steady state (Hooper and Macpherson 2010). However, this physical barrier is often not sufficient to prevent microbe-dependent inflammatory responses, and multiple other strategies have been adopted for this purpose. These include cell networks and signaling systems that prevent uptake and transport of microbes from the mucosal surface to immune inductive sites or that mediate activation of host immune cells by select microbes that can both reinforce barrier function and, potentially, regulate the repertoire of selected immune receptors. The microbiota also regulates the levels of homing receptors that guide $\mathrm{T}$ cells to diverse regions of the intestinal mucosa and thus contribute to maintenance of homeostasis. Alterations in the normal microbiota (termed dysbiosis), induced by infection or inflammation and influenced by host genetic factors, can disrupt the segregation of the microbiota from host tissues, resulting in swift and robust immunity that must be contained to prevent systemic damage. There is growing evidence that dysbiosis can result in inflammatory disease not only locally, in the gut, but also systemically.

Here, we discuss some of the strategies by which intestinal commensal microbiota and the host immune system interact to achieve a balanced but poised immune system (Fig. 1). First, we describe how a subset of mononuclear phagocytes (MNPs) in the lamina propria function to segregate luminal bacteria from cells of the adaptive immune system through a process that we call "homeostatic inhibition" and how similar cells contribute to reinforcing the intestinal barrier through activation of innate lymphoid cells. Second, we review the role of an orphan G-protein-coupled receptor, GPR15, in trafficking of regulatory $\mathrm{T}$ (Treg) cells to the large intestine, where they serve an anti-inflammatory function. We then discuss how the commensal segmented filamentous bacteria (SFB) induce Th17 cells through a process of homeostatic induction but can also contribute to autoimmunity by inflammatory induction. Finally, we provide an example of dysbiosis associated with a human autoimmune disease, rheumatoid arthritis (RA), and discuss how the specificity of $\mathrm{T}$ cells for the microbiota may contribute to the pathogenesis. 


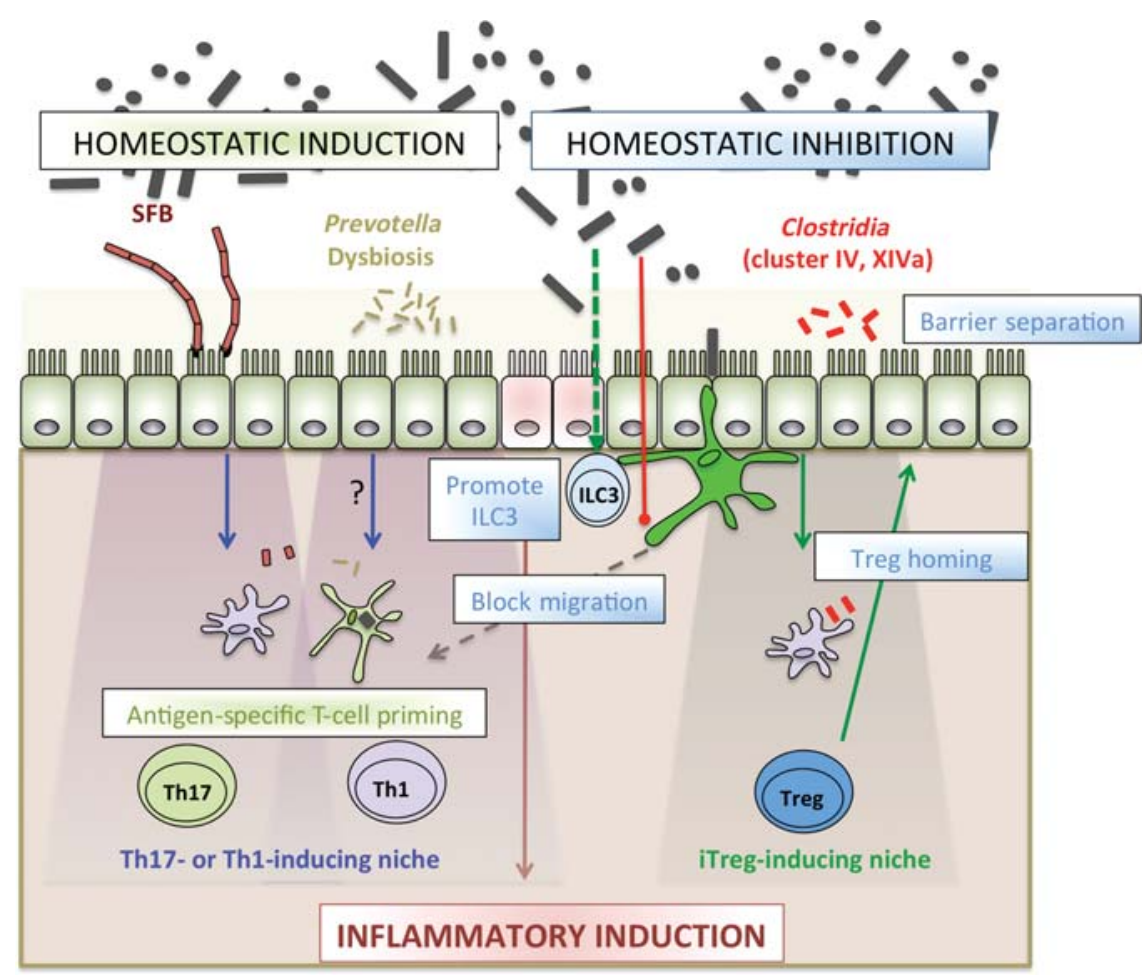

Figure 1. Roles of microbiota in maintaining balanced, yet poised, intestinal immunity. Commensals activate cellular networks to enforce compartmentalization of the microbiota. Active mechanisms of homeostatic inhibition include limiting the migration of mononuclear phagocytes (green) to draining lymph nodes, promoting ILC3 barrier support, and inducing Treg homing. Although these efforts enable compartmentalization and prevent unrestrained immune activation, homeostatic induction allows for antigenspecific T-cell polarization in the absence of inflammatory changes or barrier disruption. Segmented filamentous bacteria (SFB) exemplify a unique bacterial niche that affords Th17 induction. In the context of barrier disruption, conventional inflammatory changes are induced to wall off infection.

\section{ROLE OF CX $\mathrm{CR}_{3}{ }^{+}$MONONUCLEAR PHAGOCYTES IN COMPARTMENTALIZATION OF MICROBIOTA AND THE HOST IMMUNE SYSTEM}

At steady state, CD11 $\mathrm{c}^{+}$myeloid cells in the intestine include both pre-DC-derived conventional dendritic cells (cDC) and monocyte-derived cells that have features of either macrophages or DC (Varol et al. 2010). cDC express the integrin CD103 with or without CD11b. $\mathrm{CD}_{103}{ }^{+} \mathrm{CD} 11 \mathrm{~b}^{-}$cells are dependent on expression of the transcription factor BATF3 (Hildner et al. 2008; Edelson et al. 2010), also express cell surface CLEC9A/ DANGR1 (Poulin et al. 2012), and have the ability to cross-present antigen provided by other cells, for example, those infected by viruses. $\mathrm{CD} 103^{+} \mathrm{CD} 11 \mathrm{~b}^{+} \mathrm{DC}$ are in large part dependent on expression of Notch2 (Lewis et al. 2011), may contribute to the differentiation of Th1 7 cells, and produce IL-23 when mice are challenged with Citrobacter rodentium (Satpathy et al. 2013) or bacterial flagellin, which activates TLR5 that is selectively expressed on these cells (Kinnebrew et al. 2012). Both types of cDC migrate from the lamina propria to secondary lymphoid organs to regulate intestinal immunity. cDC also have a key role in maintaining luminal $\operatorname{IgA}$, imprint- ing gut homing on lymphocytes, and inducing the development of regulatory T cells (Sun et al. 2007).

Monocyte-derived myeloid cells express the chemokine receptor $\mathrm{CX}_{3} \mathrm{CR} 1$, which promotes formation of transepithelial dendrites and sampling of the luminal biota (Niess et al. 2005). $\mathrm{CX}_{3} \mathrm{CR} 1^{+}$cells were proposed to be nonmigratory, because they did not traffic to the mesenteric lymph nodes (MLN) upon induction of TLR7, and they are relatively poor antigen-presenting cells in culture, compared with lamina propria cDC (Schulz et al. 2009). These monocyte-derived cells have therefore recently been classified as macrophages rather than as DC. Our studies suggest that these cells can, under some circumstances, migrate to the MLN and promote the induction of microbe-specific T cells and immunoglobulins (Diehl et al. 2013). We found that the intestinal microbiota actively limit the trafficking of $\mathrm{CX}_{3} \mathrm{CR} 1^{+}$MNPs. In mice treated with antibiotics or deficient for MYD88, $\mathrm{CX}_{3} \mathrm{CR}^{+}$cells were found to take up noninvasive luminal bacteria and ferry them to the draining MLN by way of afferent lymphatics, resulting in induction of microbespecific T cells expressing IFN- $\gamma$ and antibacterial secretory IgA. Ablation of the $\mathrm{CX}_{3} \mathrm{CR}^{+}{ }^{+} \mathrm{MNPs}$ using diphtheria toxin in mice engineered to express the diphtheria toxin receptor only in $\mathrm{CD}_{11 \mathrm{c}^{+}} \mathrm{CX}_{3} \mathrm{CR} 1^{+}$cells abrogated the transport of live bacteria to the MLN. Bacteria could be 
cultured from $\mathrm{CX}_{3} \mathrm{CR} 1^{+} \mathrm{MNPs}$, but not $\mathrm{CD} 103^{+} \mathrm{cDC}$ sorted from the MLN of antibiotics-treated mice. The antibiotics-enhanced transport of luminal bacteria to the MLN was observed only in CCR7-sufficient mice, and $\mathrm{CX}_{3} \mathrm{CR} 1^{+}$cells were shown to express this chemokine receptor upon activation, consistent with the observed migratory function of these monocyte-derived cells. Thus, $\mathrm{CX}_{3} \mathrm{CR}^{+} \mathrm{MNPs}$ can migrate to draining lymph nodes and appear able to present antigen when there is perturbation of microbial-derived signaling. Disturbance of this homeostatic inhibitory pathway, due to dysbiosis or host mutations, may contribute to inflammatory bowel disease (IBD), in which there can be aberrant immune responses to commensal bacterial antigens.

$\mathrm{CX}_{3} \mathrm{CR}^{+}$MNPs also contribute to protection of the mucosal barrier by regulating the expression of the cytoprotective cytokine IL-22 by innate lymphoid cells (ROR $y$ t-expressing ILC3). In the context of inflammation, $\mathrm{CX}_{3} \mathrm{CR}^{+}$MNPs expand within the lamina propria during chemical (Zigmond et al. 2012) or infectious colitis and in IBD patients (Kamada et al. 2008). Microbial stimulation of $\mathrm{CX}_{3} \mathrm{CR}^{+}{ }^{+}$, but not $\mathrm{CD} 103^{+}$, myeloid cells induced production of IL-23, a cytokine that cooperates with IL-1 $\beta$ to induce IL-22 production in ILC3 (Longman et al., in prep.). Induced ablation of $\mathrm{CX}_{3} \mathrm{CR}^{+}{ }^{+} \mathrm{MNPs}$ rendered mice susceptible to $C$. rodentium-mediated colitis that was prevented by administration of recombinant IL-22, which acts upon intestinal epithelial cells to promote mucosal healing and production of antimicrobial peptides. Thus, under conditions of "homeostatic inhibition," expansion of monocyte-derived MNPs in the intestinal lamina propria integrate microbial signals to regulate mucosal healing via ILC3 and limit the access of luminal bacteria to the draining lymph nodes, preventing activation of adaptive immunity (Fig. 2).

\section{CONTRIBUTION OF Treg CELLS TO INTESTINAL BARRIER FUNCTION}

Foxp3-expressing Treg cells make up a large fraction of $\mathrm{CD}^{+} \mathrm{T}$ cells in the small and large intestine and have critical functions in maintenance of tolerance toward the commensal microbiota and food antigens (Littman and Rudensky 2010). Although a fraction of intestinal Treg cells is derived from thymus, many other Treg cells are induced by the commensal microbiota. Cluster IV and XIVa Clostridia were found to be effective inducers of Treg cells in the large intestine, the site housing the largest number of microbes (Atarashi et al. 2010). In addition, both IL-10 and Treg cells are required to restrain colitis-inducing $\mathrm{T}$ cells in the presence of colitogenic bacteria such as Helicobacter hepaticus. Thus, IL10-deficient mice develop spontaneous colitis in mice colonized with $H$. hepaticus, and transfer of Treg-depleted $\mathrm{T}$ cells into immunodeficient mice results in colitis that is dependent on the presence of microbiota (Maloy et al. 2003). Although there is evidence that many if not most Treg cells have T-cell antigen receptors (TCRs) specific for commensal microbial products (Lathrop et al. 2011), further analysis is needed to determine the antigen specificity of intestinal Treg cells in a natural repertoire.

Trafficking of $\mathrm{T}$ cells to the small intestine is regulated by retinoic-acid-mediated induction of the chemokine receptor CCR9 and the integrin $\alpha_{4} \beta_{7}$ (Iwata et al. 2004). This induction is thought to occur upon trafficking of RAproducing DC to the draining MLN. The activated T cells are then directed to sites of ligand expression in the small intestine after their release into the circulation. We recently found that another G-protein-coupled receptor, GPR15, directs T-cell migration to the large intestine in concert with $\alpha_{4} \beta_{7}$ (Kim et al. 2013). In the mouse, GPR15 was preferentially expressed on large intestine Treg cells, and mice deficient for GPR 15 had increased susceptibility in both infectious and anti-CD40-induced colitis models. The colitis could be prevented if GPR15-deficient mice were reconstituted with GPR15-sufficient Treg cells. Selective migration of GPR15-expressing $\mathrm{T}$ cells to the large intestine was independent of microbiota, but the induction of GPR 15 on T cells was attenuated in germfree or antibiotics-treated mice. The microbiota thus appear to regulate the expression of this homing receptor on $\mathrm{T}$ cells, particularly on Treg cells, but the mechanism for this process is yet to be fully elucidated. Transforming growth factor $\beta$ (TGF- $\beta$ ) appears to influence GPR15 expression, but RA does not have a role. Outstanding questions include the nature of the GPR15 ligand, which is likely selectively expressed in endothelial cells within the large intestine, and the site of GPR15 induction. We postulate that GPR 15 is preferentially induced in lymph nodes by specialized MNPs that drain the large intestinal lamina propria, thus priming Treg cells to migrate to the large intestine, where they contribute to maintaining a homeostatic balance and integrity of the epithelial barrier (Fig. 3). GPR15 is also preferentially expressed by lymphocytes in the human large intestine, suggesting that it serves a key function in trafficking of these cells to this mucosal site. Targeting of GPR15 may allow for manipulation of effector and regulatory $\mathrm{T}$-cell populations in the large intestine that could be applied to IBD therapies or to attenuating graft versus host disease in allogeneic bone marrow transplantation.

\section{HOMEOSTATIC INDUCTION OF EFFECTOR T CELLS BY SPECIALIZED COMMENSAL MICROBES}

Although there exist multiple strategies to segregate microbiota from the immune response, as described above, there also appear to be bacterial species with unique abilities to induce specific T-cell differentiation pathways in the absence of barrier disruption and inflammatory damage. One example is that of Treg induction by Clostridia species, potentially through a mechanism that involves production of short-chain fatty acids that act by way of both immune and nonimmune cells to induce Foxp3 expression in $\mathrm{CD}^{+}{ }^{+} \mathrm{T}$ cells (Atarashi et al. 2010, 2013; Arpaia et al. 2013; Furusawa et al. 2013). Our group 


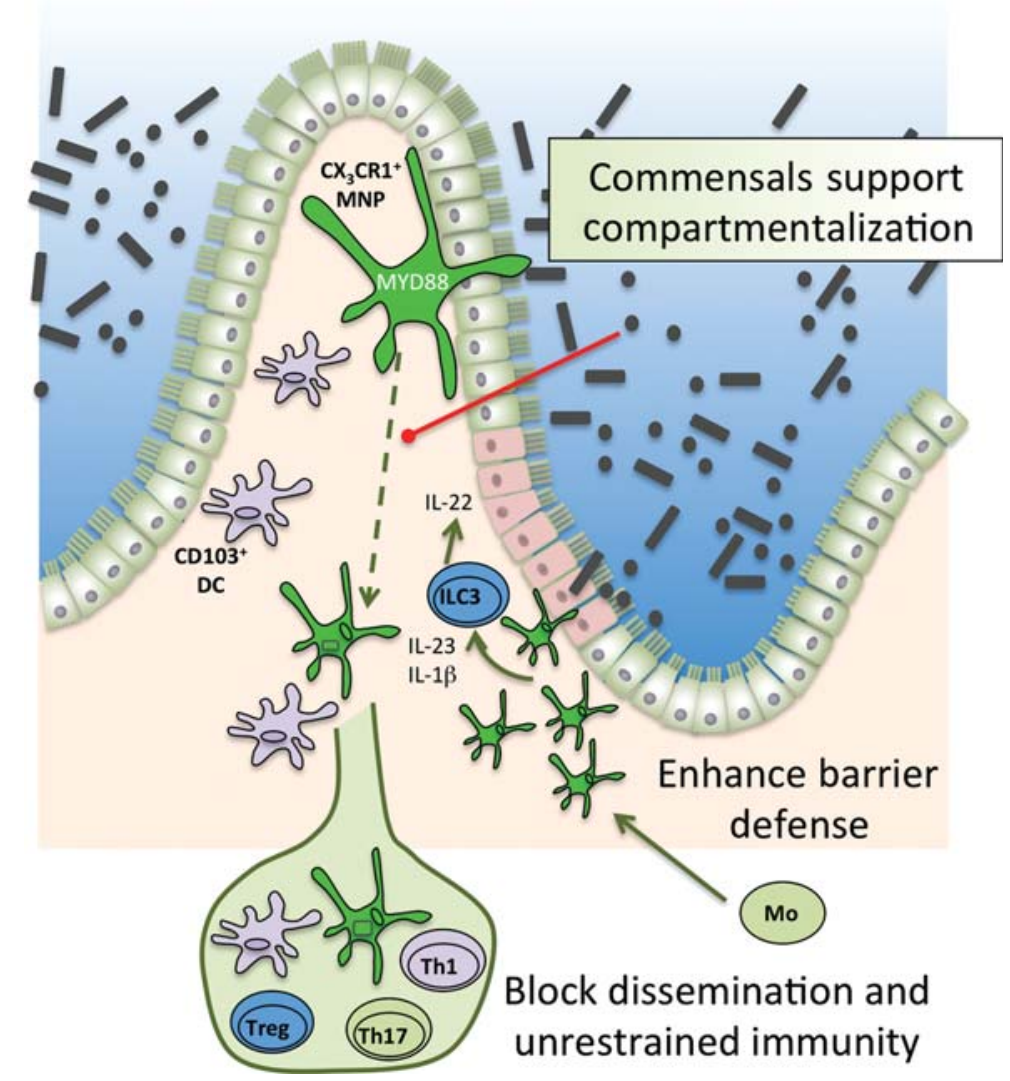

Figure 2. Homeostatic inhibition maintained by microbial regulation of mononuclear phagocytes. At steady state, $\mathrm{CX}_{3} \mathrm{CR} 1^{+} \mathrm{MNPs}$ (green) are able to extend transepithelial dendrites to sample luminal microbiota. Signals from luminal microbiota limit $\mathrm{CX}_{3} \mathrm{CR}^{+}$ MNP migration to MLN by way of MYD88 signaling (red line). In the setting of dysbiosis, $\mathrm{CX}_{3} \mathrm{CR} 1^{+}$MNPs can traffic luminal microbes to the MLN and promote proinflammatory immune responses. In the setting of barrier injury (indicated in pink), $\mathrm{CX}_{3} \mathrm{CR} 1^{+}$ MNPs expand from monocyte (Mo) precursors. Microbial signals support $\mathrm{CX}_{3} \mathrm{CR} 1^{+}$MNP production of IL-23 and IL-1 $\beta$ which, subsequently, induce ILC3 production of IL-22 to promote mucosal healing and antimicrobial peptide production.

has been studying the induction of Th17 cells by another gram-positive spore-forming anaerobe, SFB, which are most closely related to Clostridia but have a severely restricted genome that renders them auxotrophic for numerous biosynthetic building blocks (Ivanov et al. 2009; Sczesnak et al. 2011). SFB are found to be closely associated with the intestinal epithelium in the terminal ileum. They successfully penetrate the mucin layer and interact directly with the plasma membrane of the intestinal epithelial cells, resulting in actin polymerization around the site of contact (Jepson et al. 1993). SFB have been described not only in rodents, but also in many other mammalian species. It was reported that SFB 16S rRNA gene sequences could be amplified from young infants in China (Yin et al. 2013), but there are no other reports on human association and no metagenomic data to confirm the original observation.

Th17 cells are ROR $\gamma$ t-expressing $\mathrm{CD}^{+} \mathrm{T}$ cells that produce IL-17a, IL-17f, and IL-22 cytokines that protect the mucosal barrier by diverse mechanisms (Littman and Rudensky 2010). IL-17 cytokines induce local production of chemokines that attract neutrophils and of granulocyte colony-stimulating factor (G-CSF), which promotes neu- trophil differentiation. They also promote production of metal metalloproteases and vascular endothelial growth factor VEGF, involved in angiogenesis and tissue remodeling, and induction of epithelial genes involved in forming cellular junctions. Together, these activities function to protect the mucosa from infection by extracellular bacteria and fungi but can also result in inflammatory damage. Th17 cells differentiate in response to various combinations of IL-6, IL-1 $\beta$, IL-21, IL-23, and TGF- $\beta$ and have been implicated in multiple autoimmune diseases and other inflammatory conditions (Cua et al. 2003; Hue et al. 2006; Kullberg et al. 2006; Zhou and Littman 2009). They are most abundant at mucosal surfaces, particularly in the intestinal lamina propria, where they make up as many as $30 \%$ of the $\mathrm{CD}^{+} \mathrm{T}$ cells.

Th17 cells are absent in germ-free mice that lack any microbiota, and they can be reconstituted by monoassociation with SFB (which is propagated in gnotobiotic mice because it has yet to be cultured) (Ivanov et al. 2009). However, the mechanism of Th17 cell induction is not yet well characterized. It appears that TLR, inflammasome, nor dectin signaling is required, suggesting that there may be redundant innate signals that are individually 


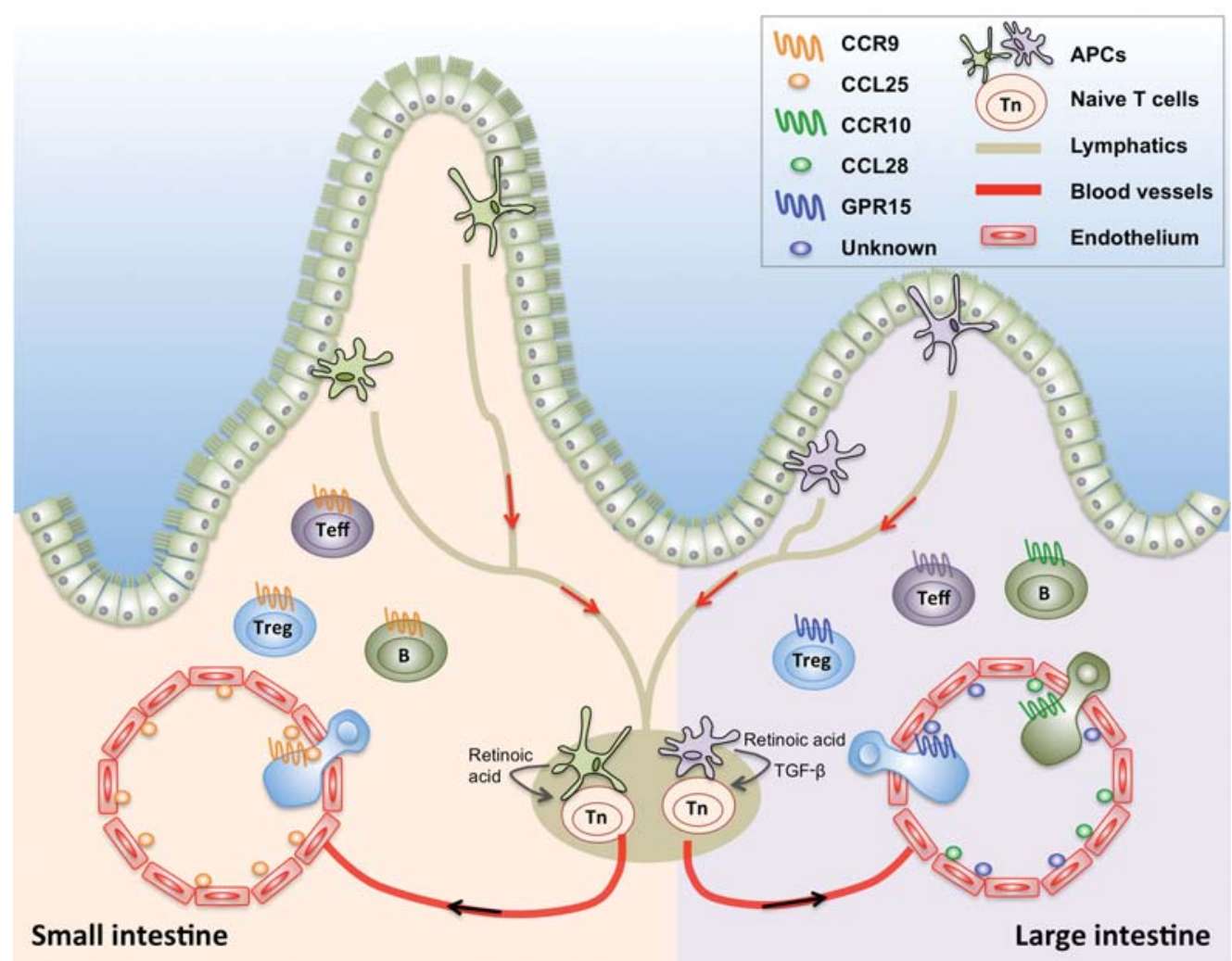

Figure 3. Homeostatic inhibition maintained by homing cues for Treg cells. Antigen-presenting cells exposed to environmental cues such as retinoic acid (small intestine, large intestine) and TGF- $\beta$ (large intestine) migrate to the mesenteric lymph nodes where they activate naive T cells. Endothelial cell expression of the corresponding ligands for homing receptors (CCL25 in the small intestine; CCL28 and unknown GPR15 ligand in the large intestine) enables activated T cells expressing unique homing receptors (CCR9 for the small intestine; CCR10 and GPR15 for the large intestine) to go back to the site of antigen capture.

sufficient or that direct binding of SFB to epithelium contributes to the process. Colonization of mice with SFB results in rapid up-regulation of the serum amyloid A proteins in intestinal epithelial cells, and SAA1 and/or SAA2 may induce the activation of MNPs specialized to polarize Th17 cells (Ivanov et al. 2009). Ongoing studies should help to clarify the potential roles of innate signals and of SAAs in SFB-mediated induction of Th17 cells.

Colonization of mice with SFB induces Th17 cells not only in the small intestine lamina propria but also in the large intestine, where these cells can protect from C. rodentium-mediated colitis (Ivanov et al. 2009), and systemically, where the result can be detrimental, for example, spontaneous arthritis in the $\mathrm{K} / \mathrm{BxN}$ mouse model (Wu et al. 2010), in which the disease is dependent on intestinal microbiota. Similarly, monoassociation of mice with SFB exacerbates the course of experimental autoimmune encephalomyelitis (Lee et al. 2010), a paralytic autoimmune disease induced by immunization with myelin protein and mediated by Th17 cells. Thus, Th17 cells induced locally in the small intestinal lamina propria can protect the gut barrier from pathogens but can also trigger or exacerbate systemic autoimmunity.

The influence on distal autoimmune processes by intestinal SFB-induced Th17 cells raises the question of what antigens are recognized by the TCRs expressed on these
$\mathrm{CD}^{+} \mathrm{T}$ cells. TCR-transgenic mice have been used to probe whether Th17 cell induction is due to the microbiota-conditioned microenvironment or to direct recognition of microbe-encoded antigens. Microbial colonization was reported sufficient to induce IL- $17^{+}$ROR $y \mathrm{t}^{+}$Th17 cells in two different TCR-transgenic mouse strains in the absence of cognate antigen (Lochner et al. 2010). However, it is unclear whether the induction was dependent on SFB, because these mice contained a complex microbiota and there was no comparison with SFB-deficient mice. We have examined ovalbumin (OVA)-specific TCR-transgenic OT-II mice colonized with SFB and have not observed Th17 cells among the OVA-specific T cells. Moreover, we have undertaken an examination of the antigen specificity of Th17 cells in both SFB-colonized C57BL/ 6 mice purchased from Taconic Farms (TAC) and in SFB-free mice from the Jackson Laboratory (JAX) (Yang et al., in prep.). Analysis of bulk Th17 cells sorted from the small intestinal lamina propria of TAC mice revealed that most of the cells were specific for SFB antigen presented by MHC class II. In contrast, the nonTh17 cells from the gut did not respond to SFB. Th17 cells from JAX mice also responded to bacterial antigen, although the specific bacteria have not been identified. Thus, the bulk of intestinal Th17 cells appears to be specific for antigen encoded by the microbiota. 
By expressing TCRs from single Th17 cells in a reporter hybridoma, we found that most TCRs were specific for peptides from either of two proteins expressed by SFB. We generated several lines of transgenic mice expressing TCRs specific for SFB peptides and transferred CD4 ${ }^{+}$ $\mathrm{T}$ cells from these mice into SFB-colonized or SFB-free mice. The transferred cells expanded only in SFB-colonized recipient mice, and almost all became Th17 cells in the MLN and, subsequently, in the small intestinal lamina propria. In contrast, OT-II $\mathrm{T}$ cells cotransferred with SFB-specific T cells did not acquire the Th17 phenotype even when the mice were gavaged with soluble OVA. Consistent with cognate bacterial antigen recognition guiding the phenotype of the differentiating T-helper cells, when mice were colonized with both SFB and Listeria monocytogenes, SFB-specific T cells became Th17 cells and Listeria antigen-specific T cells differentiated into Th1 cells, even though both bacterial species were present in the small intestine. This is in contrast to inflammatory $\mathrm{T}$-cell responses that can be generated against commensals in the context of a strong Th1 response as observed after infection with Toxoplasma gondii (Hand et al. 2012). The cellular and molecular basis of this differential induction of T-cell programs remains to be elucidated. Potential mechanisms include bacteria-specific instructional signals guiding the MNPs that present the bacterial antigens to express a distinct set of cytokines and interaction of each type of specialized bacterial species with a unique class of MNPs that can both present its antigens to naive $T$ cells and polarize those cells to the appropriate effector subset. The latter mechanism could involve interaction of specialized bacteria with distinct niches in the gastrointestinal tract, as depicted in the model in Figure 4.
How SFB-induced Th17 cells that are largely specific for SFB antigen can provoke systemic autoimmunity remains unresolved. We can envision several possible mechanisms: (1) A subset of SFB-specific Th17 cells have TCRs that are cross-reactive with host antigens supplied by the diverse affected tissues, also known as molecular mimicry; (2) the SFB-specific Th17 cells exert a bystander effect on $\mathrm{T}$ cells with specificity for self-antigen, converting them to Th17 cells or double producers for IL-17 and IFN- $\gamma$, which are often found in inflammatory foci; or (3) the SFB-conditioned microenvironment changes the threshold for activation of self-reactive effector cells or Treg cells, resulting in self-reactive effector Th17 cells. In this last scenario, SFB-specific Th17 cells would be dispensable for disease onset.

The role of SFB in the induction of Th17 cells and of systemic Th17-dependent autoimmune disease thus serves as a model that can be further exploited to attain a better understanding of how specialized bacteria elicit specific host effector functions at steady state and how such functions can result in barrier protection versus systemic autoimmune disease. This model system allows for investigation of the site of microbiota-dependent induction of effector $\mathrm{T}$ cells, the roles of cells and molecules of the innate immune system in induction of Th17 cells, and the mechanism of Th17-mediated autoimmunity. A mechanistic understanding of this system may provide critical insight into pathogenesis of human autoimmune disease and into the efficacy of diverse therapeutic strategies, for example, the contrasting clinical efficacy of anti-IL-17 therapy in human IBD (Hueber et al. 2012) compared with psoriasis (Hueber et al. 2010) and RA (Genovese et al. 2014).

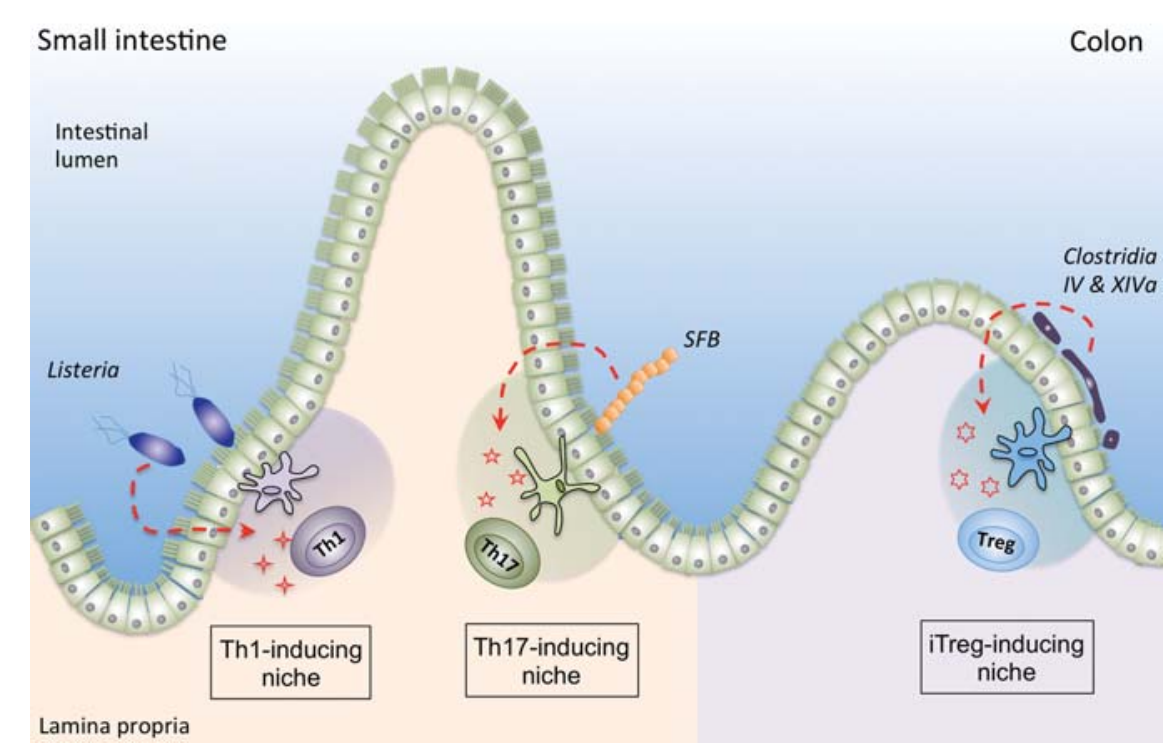

Figure 4. Homeostatic induction of T-cell polarization by specialized bacteria. Specialized intestinal bacteria such as SFB and Clostridial species occupy intestinal niches distinct from pathogens such as Listeria monocytogenes. Differential signals induced at these distinct niches may induce the expression of divergent polarizing cytokines and/or engage unique subsets of MNPs that induce and sustain antigen-specific, pro-inflammatory or anti-inflammatory T-helper cells. 


\section{ROLE OF MICROBIOTA IN HUMAN AUTOIMMUNE DISEASE}

The studies with SFB inspired us to examine potential links between dysbiosis or distinct microbiota signatures and autoimmune disease in humans. Based on the link of SFB colonization and onset of arthritis in the $\mathrm{K} / \mathrm{BxN}$ mouse model, we chose to study cohorts of patients with RA (Scher et al. 2013). We examined the fecal microbiota from patients and healthy control subjects recruited through the rheumatology clinic at Bellevue Hospital in New York. The patient cohorts included individuals with new-onset untreated RA (NORA) as well as subjects who had long-term RA and had received multiple treatment regimens. We performed $16 \mathrm{~S}$ rRNA gene sequencing, which allows for taxon classification, as well as shotgun deep sequencing, which allows for species identification. Remarkably, $75 \%$ of the NORA patients were colonized with the gram-negative anaerobe Prevotella copri, compared with $21 \%$ of healthy control subjects and $12 \%$ of the chronic RA patients. In studies of healthy individuals in the Human Microbiome Project (HMP) cohort in the United States and the Metagenomics of the Human Intestinal Tract (MetaHIT) cohort in Europe, P. copri was observed in $12 \%-15 \%$ of the samples, consistent with our observations.

Studies are currently underway to understand the potential contribution of $P$. copri to the pathogenesis of RA. Partial assembly of $P$. copri sequences from metagenomic data indicated that some gene clusters were preferentially present in either patient-associated or healthy control $P$. copri genomes. Although we cannot at present interpret the functions of these genes, there is the possibility that they contribute to virulence when they are either present or absent from the $P$. copri genome. In mice with defects in the inflammasome pathway, a Prevotella-dominated dysbiosis was found to result in enhanced susceptibility to chemically induced colitis (Elinav et al. 2011). Although the Prevotella species differs between mice and humans, colonization of mice with the reference $P$. copri strain (DSM\#18205) resulted in a mild increase in susceptibility to chemically induced colitis. It is possible that some bacteria in this phylum have the potential to induce pathogenic changes in the host immune system, but it is difficult to know if this is related to potential pathogenicity of this bacterium in humans. Notably, we observed a significantly higher relative abundance of $P$. copri in RA patients without human leukocyte antigen (HLA) class II DRB1 risk alleles (called "shared epitope" alleles), suggesting that $P$. copri itself may serve as an inflammatory risk factor or act as a diagnostic surrogate for an underlying causative factor. At this stage, however, we cannot distinguish the $P$. copri expansion observed in NORA patients between its having a causal influence in the disease, akin to that of SFB in mice with arthritis, and its being a consequence of the disease, for example, due to increased systemic inflammation. We are currently culturing $P$. copri from NORA patients and from healthy individuals and will compare their potential for inducing inflammatory changes both within the intestine and systemically.

\section{CONCLUSIONS}

In this overview, we attempt to describe several strategies by which intestinal commensal microbes regulate host immune processes. The physical barriers that separate microbiota from host tissues are maintained and reinforced by cellular networks of homeostatic inhibition that prevent unrestrained immune activation. In contrast to this compartmentalization, mechanisms of homeostatic induction enable distinct microbial species to direct antigen-specific T-cell differentiation pathways in the absence of inflammation or barrier compromise. These inductive processes include regulation not only of Th17 and Treg cell differentiation, which have been most extensively investigated, but also ILC3 production of IL-22. On the other hand, dysbiosis, which can be induced by antibiotics (Diehl et al. 2013) or enteric infection (Hand et al. 2012), impairs homeostatic inhibition and can result in acute inflammatory disease with the long-term consequence of an expanded memory T-cell repertoire against commensals that breach the barrier. Both homeostatic induction and dysbiosis-mediated induction of microbiotaspecific $\mathrm{T}$ cells may contribute to the selection of a primed T-cell repertoire. Humans harbor memory T cells specific for viruses to which they have not been exposed ( $\mathrm{Su}$ et al. 2013). It is tempting to speculate that microbiota-host mutualism provides a large pool of microbial antigens that may have been evolutionarily selected to prime host T cells (and, potentially, B cells as well) that protect against pathogenic microbes. It will be of interest to determine if there are differences in antigen specificities of $\mathrm{T}$ cells elicited by homeostatic inducers such as SFB versus inflammation-associated inducers, such as $T$. gondii or other pathogens, and if such T cells differ in their potential to promote systemic inflammatory processes.

At this time, we cannot estimate how many among the hundreds of bacterial species in the gut microbiota have the capacity for homeostatic induction of $\mathrm{T}$ cells. With current tools, it will be possible to determine which bacterial species induce distinct $\mathrm{T}$-cell effector subsets and whether such cells have TCRs specific for bacterial antigens. Such an approach may help to determine whether $P$. copri resembles SFB in its capacity to induce bacterialspecific effector $\mathrm{T}$ cells. Although it remains unclear whether the dysbiosis associated with IBD (Peterson et al. 2008) or RA (Scher et al. 2013) is causative of disease, commensal-induced microenvironments may guide human T-cell polarization (Zielinski et al. 2012). It will thus be of particular interest to compare $P$. copri-specific T-cell responses in healthy $P$. copri-colonized individuals and NORA patients.

An improved mechanistic understanding of "homeostatic inducers" in shaping local and systemic T-cell repertoires offers potential diagnostic and therapeutic opportunities. It may be possible to engineer commensal microbes to deliver antigens for the induction of effector $\mathrm{T}$ cells, for example, for protective vaccination, or Treg cells, for tissue-specific induction of tolerance. Human immunodeficiency virus attacks $\mathrm{CD}^{+}{ }^{+} \mathrm{T}$ cells in the intestinal lamina propria early after transmission and de- 
pletes Th17 cells disproportionately. Mucosal vaccines that elicit Th17 cells or other effector cells specific for HIV antigens may thus provide a means for protection early after infection. Advances in this area will require partnerships between immunologists and microbiologists as we begin to deconvolute the highly complex microbiome and assign specific functions to individual bacteria and to microbial communities that function in concert to communicate with our immune system.

\section{ACKNOWLEDGMENTS}

We thank members of our laboratory and our many collaborators for their contributions to the studies described in this overview. The work was supported by the American Cancer Society and National Institutes of Health (NIH) T32 CA009161 (G.E.D.), NIH K08 DK099381 (R.S.L.), NIH T32 AI100853 (S.V.K.), and the Howard Hughes Medical Institute (D.R.L.).

\section{REFERENCES}

Arpaia N, Campbell C, Fan X, Dikiy S, van der Veeken J, deRoos P, Liu H, Cross JR, Pfeffer K, Coffer PJ, et al. 2013. Metabolites produced by commensal bacteria promote peripheral regulatory T-cell generation. Nature 504: 451-455.

Atarashi K, Tanoue T, Shima T, Imaoka A, Kuwahara T, Momose Y, Cheng G, Yamasaki S, Saito T, Ohba Y, et al. 2010. Induction of colonic regulatory $\mathrm{T}$ cells by indigenous Clostridium species. Science 331: 337-341.

Atarashi K, Tanoue T, Oshima K, Suda W, Nagano Y, Nishikawa H, Fukuda S, Saito T, Narushima S, Hase K, et al. 2013. Treg induction by a rationally selected mixture of Clostridia strains from the human microbiota. Nature 500: 232-236.

Cua DJ, Sherlock J, Chen Y, Murphy CA, Joyce B, Seymour B, Lucian L, To W, Kwan S, Churakova T, et al. 2003. Interleukin-23 rather than interleukin-12 is the critical cytokine for autoimmune inflammation of the brain. Nature 421: 744-748.

Diehl GE, Longman RS, Zhang JX, Breart B, Galan C, Cuesta A, Schwab SR, Littman DR. 2013. Microbiota restricts trafficking of bacteria to mesenteric lymph nodes by CX(3)CR1(hi) cells. Nature 494: 116-120.

Edelson BT, Kc W, Juang R, Kohyama M, Benoit LA, Klekotka PA, Moon C, Albring JC, Ise W, Michael DG, et al. 2010. Peripheral CD103+ dendritic cells form a unified subset developmentally related to CD8alpha + conventional dendritic cells. J Exp Med 207: 823-836.

Elinav E, Strowig T, Kau AL, Henao-Mejia J, Thaiss CA, Booth CJ, Peaper DR, Bertin J, Eisenbarth SC, Gordon JI, et al. 2011. NLRP6 inflammasome regulates colonic microbial ecology and risk for colitis. Cell 145: 745-757.

Furusawa Y, Obata Y, Fukuda S, Endo TA, Nakato G, Takahashi D, Nakanishi Y, Uetake C, Kato K, Kato T, et al. 2013. Commensal microbe-derived butyrate induces the differentiation of colonic regulatory T cells. Nature 504: 446-450.

Genovese MC, Durez P, Richards HB, Supronik J, Dokoupilova E, Aelion JA, Lee SH, Codding CE, Kellner H, Ikawa T, et al. 2014. One-year efficacy and safety results of secukinumab in patients with rheumatoid arthritis: Phase II, dose-finding, double-blind, randomized, placebo-controlled study. J Rheumatol 41: 414-421.

Hand TW, Dos Santos LM, Bouladoux N, Molloy MJ, Pagan AJ, Pepper M, Maynard CL, Elson CO III, Belkaid Y. 2012. Acute gastrointestinal infection induces long-lived microbiota-specific T cell responses. Science 337: 1553-1556.

Hildner K, Edelson BT, Purtha WE, Diamond M, Matsushita H, Kohyama M, Calderon B, Schraml BU, Unanue ER, Diamond
MS, et al. 2008. Batf3 deficiency reveals a critical role for CD8alpha+ dendritic cells in cytotoxic T cell immunity. Science 322: 1097-1100.

Hooper LV, Macpherson AJ. 2010. Immune adaptations that maintain homeostasis with the intestinal microbiota. Nat Rev Immunol 10: 159-169.

Hue S, Ahern P, Buonocore S, Kullberg MC, Cua DJ, McKenzie BS, Powrie F, Maloy KJ. 2006. Interleukin-23 drives innate and T cell-mediated intestinal inflammation. $J \operatorname{Exp} \operatorname{Med} 203$ : 2473-2483.

Hueber W, Patel DD, Dryja T, Wright AM, Koroleva I, Bruin G, Antoni C, Draelos Z, Gold MH, Durez P, et al. 2010. Effects of AIN457, a fully human antibody to interleukin-17A, on psoriasis, rheumatoid arthritis, and uveitis. Sci Transl Med 2: $52 \mathrm{ra} 72$.

Hueber W, Sands BE, Lewitzky S, Vandemeulebroecke M, Reinisch W, Higgins PD, Wehkamp J, Feagan BG, Yao MD, Karczewski M, et al. 2012. Secukinumab, a human anti-IL-17A monoclonal antibody, for moderate to severe Crohn's disease: Unexpected results of a randomised, double-blind placebo-controlled trial. Gut 61: 1693-1700.

Ivanov II, Atarashi K, Manel N, Brodie EL, Shima T, Karaoz U, Wei D, Goldfarb KC, Santee CA, Lynch SV, et al. 2009. Induction of intestinal Th17 cells by segmented filamentous bacteria. Cell 139: 485-498.

Iwasaki A, Medzhitov R. 2004. Toll-like receptor control of the adaptive immune responses. Nat Immunol 5: 987-995.

Iwata M, Hirakiyama A, Eshima Y, Kagechika H, Kato C, Song SY. 2004. Retinoic acid imprints gut-homing specificity on T cells. Immunity 21: 527-538.

Jepson MA, Clark MA, Simmons NL, Hirst BH. 1993. Actin accumulation at sites of attachment of indigenous apathogenic segmented filamentous bacteria to mouse ileal epithelial cells. Infect Immun 61: 4001-4004.

Kamada N, Hisamatsu T, Okamoto S, Chinen H, Kobayashi T, Sato T, Sakuraba A, Kitazume MT, Sugita A, Koganei K, et al. 2008. Unique CD14 intestinal macrophages contribute to the pathogenesis of Crohn disease via IL-23/IFN-gamma axis. J Clin Invest 118: 2269-2280.

Kim SV, Xiang WV, Kwak C, Yang Y, Lin XW, Ota M, Sarpel U, Rifkin DB, Xu R, Littman DR. 2013. GPR15-mediated homing controls immune homeostasis in the large intestine mucosa. Science 340: 1456-1459.

Kinnebrew MA, Buffie CG, Diehl GE, Zenewicz LA, Leiner I, Hohl TM, Flavell RA, Littman DR, Pamer EG. 2012. Interleukin 23 production by intestinal CD103 $(+) \mathrm{CD} 11 \mathrm{~b}(+)$ dendritic cells in response to bacterial flagellin enhances mucosal innate immune defense. Immunity 36: 276-287.

Kullberg MC, Jankovic D, Feng CG, Hue S, Gorelick PL, McKenzie BS, Cua DJ, Powrie F, Cheever AW, Maloy KJ, et al. 2006. IL-23 plays a key role in Helicobacter hepaticus-induced T cell-dependent colitis. J Exp Med 203: 24852494.

Lathrop SK, Bloom SM, Rao SM, Nutsch K, Lio CW, Santacruz N, Peterson DA, Stappenbeck TS, Hsieh CS. 2011. Peripheral education of the immune system by colonic commensal microbiota. Nature 478: 250-254.

Lee YK, Menezes JS, Umesaki Y, Mazmanian SK. 2010. Microbes and Health Sackler Colloquium: Proinflammatory Tcell responses to gut microbiota promote experimental autoimmune encephalomyelitis. Proc Natl Acad Sci 108 Suppl 1: 4615-4622.

Lewis KL, Caton ML, Bogunovic M, Greter M, Grajkowska LT, $\mathrm{Ng}$ D, Klinakis A, Charo IF, Jung S, Gommerman JL, et al. 2011. Notch2 receptor signaling controls functional differentiation of dendritic cells in the spleen and intestine. Immunity 35: $780-791$.

Littman DR, Rudensky AY. 2010. Th17 and regulatory T cells in mediating and restraining inflammation. Cell 140: $845-$ 858.

Lochner M, Berard M, Sawa S, Hauer S, Gaboriau-Routhiau V, Fernandez TD, Snel J, Bousso P, Cerf-Bensussan N, Eberl G. 2010. Restricted microbiota and absence of cognate TCR an- 
tigen leads to an unbalanced generation of Th17 cells. $J$ Immunol 186: 1531-1537.

Maloy KJ, Salaun L, Cahill R, Dougan G, Saunders NJ, Powrie F. 2003. CD4 + CD25+ T(R) cells suppress innate immune pathology through cytokine-dependent mechanisms. $J$ Exp Med 197: 111-119.

Metchnikoff E, Mitchell PC. 1907. The prolongation of life; optimistic studies. W. Heinemann; G.P. Putnam's Sons, New York.

Niess JH, Brand S, Gu X, Landsman L, Jung S, McCormick BA, Vyas JM, Boes M, Ploegh HL, Fox JG, et al. 2005. CX3CR1mediated dendritic cell access to the intestinal lumen and bacterial clearance. Science 307: 254-258.

Peterson DA, Frank DN, Pace NR, Gordon JI. 2008. Metagenomic approaches for defining the pathogenesis of inflammatory bowel diseases. Cell Host Microbe 3: 417-427.

Poulin LF, Reyal Y, Uronen-Hansson H, Schraml BU, Sancho D, Murphy KM, Hakansson UK, Ferreira Moita L, Agace WW, Bonnet D, et al. 2012. DNGR-1 is a specific and universal marker of mouse and human Batf3-dependent dendritic cells in lymphoid and nonlymphoid tissues. Blood 119: 6052 6062.

Satpathy AT, Briseno CG, Lee JS, Ng D, Manieri NA, Kc W, Wu X, Thomas SR, Lee WL, Turkoz M, et al. 2013. Notch2dependent classical dendritic cells orchestrate intestinal immunity to attaching-and-effacing bacterial pathogens. Nat Immunol 14: 937-948.

Scher JU, Sczesnak A, Longman RS, Segata N, Ubeda C, Bielski C, Rostron T, Cerundolo V, Pamer EG, Abramson SB, et al. 2013. Expansion of intestinal Prevotella copri correlates with enhanced susceptibility to arthritis. Elife 2: e01202.

Schulz O, Jaensson E, Persson EK, Liu X, Worbs T, Agace WW, Pabst O. 2009. Intestinal CD103+, but not CX3CR1+, antigen sampling cells migrate in lymph and serve classical dendritic cell functions. J Exp Med 206: 3101-3114.
Sczesnak A, Segata N, Qin X, Gevers D, Petrosino JF, Huttenhower C, Littman DR, Ivanov II. 2011. The genome of th17 cell-inducing segmented filamentous bacteria reveals extensive auxotrophy and adaptations to the intestinal environment. Cell Host Microbe 10: 260-272.

Su LF, Kidd BA, Han A, Kotzin JJ, Davis MM. 2013. Virusspecific $\mathrm{CD} 4(+)$ memory-phenotype $\mathrm{T}$ cells are abundant in unexposed adults. Immunity 38: 373-383.

Sun CM, Hall JA, Blank RB, Bouladoux N, Oukka M, Mora JR, Belkaid Y. 2007. Small intestine lamina propria dendritic cells promote de novo generation of Foxp3 T reg cells via retinoic acid. J Exp Med 204: 1775-1785.

Varol C, Zigmond E, Jung S. 2010. Securing the immune tightrope: Mononuclear phagocytes in the intestinal lamina propria. Nat Rev Immunol 10: 415-426.

Wu HJ, Ivanov II, Darce J, Hattori K, Shima T, Umesaki Y, Littman DR, Benoist C, Mathis D. 2010. Gut-residing segmented filamentous bacteria drive autoimmune arthritis via $\mathrm{T}$ helper 17 cells. Immunity 32: 815-827.

Yin Y, Wang Y, Zhu L, Liu W, Liao N, Jiang M, Zhu B, Yu HD, Xiang C, Wang X. 2013. Comparative analysis of the distribution of segmented filamentous bacteria in humans, mice and chickens. ISME J 7: 615-621.

Zhou L, Littman DR. 2009. Transcriptional regulatory networks in Th17 cell differentiation. Curr Opin Immunol 21: 146-152.

Zielinski CE, Mele F, Aschenbrenner D, Jarrossay D, Ronchi F, Gattorno M, Monticelli S, Lanzavecchia A, Sallusto F. 2012. Pathogen-induced human TH17 cells produce IFNgamma or IL-10 and are regulated by IL-1beta. Nature 484: $514-518$

Zigmond E, Varol C, Farache J, Elmaliah E, Satpathy AT, Friedlander G, Mack M, Shpigel N, Boneca IG, Murphy KM, et al. 2012. Ly6 $\mathrm{C}^{\mathrm{hi}}$ monocytes in the inflamed colon give rise to proinflammatory effector cells and migratory antigen-presenting cells. Immunity 37: 1076-1090. 


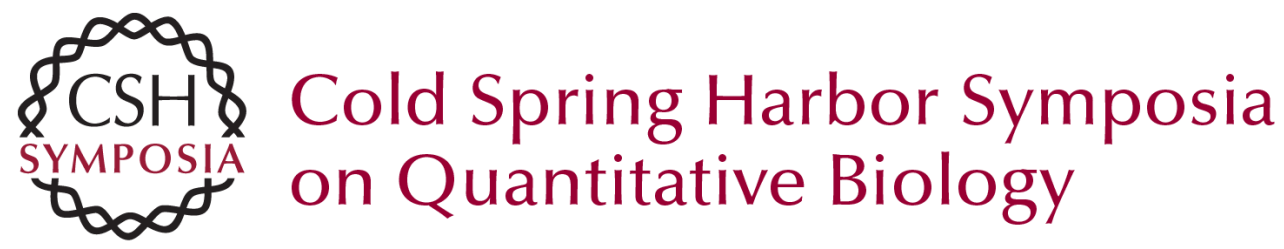

\section{Microbiota: Host Interactions in Mucosal Homeostasis and Systemic Autoimmunity}

Randy S. Longman, Yi Yang, Gretchen E. Diehl, et al.

Cold Spring Harb Symp Quant Biol 2013 78: 193-201 originally published online June 9, 2014 Access the most recent version at doi:10.1101/sqb.2013.78.020081

References This article cites 43 articles, 14 of which can be accessed free at: http://symposium.cshlp.org/content/78/193.full.html\#ref-list-1

License

Email Alerting Receive free email alerts when new articles cite this article - sign up in Service the box at the top right corner of the article or click here. 